\title{
Vehicle Scrappage and Gasoline Policy
}

\author{
By Mark R. Jacobsen and Arthur A. van Benthem
}

\section{Online Appendix}

\section{Appendix A Alternative First Stage and Reduced Form Specifi- cations}

\section{Reduced Form Using MPG Quartiles}

The reduced form of our scrap elasticity estimates is the relation between gasoline prices and scrap rates. Analagous to the first stage results in Section B, we show the results for a reduced form specification using fuel-economy quartiles. We repeat the specification in equation (5), now considering scrap rates in place of prices:

$$
y_{a m t}=\alpha_{a m}+\alpha_{a t}+\boldsymbol{\beta}_{\mathbf{1}}{ }^{\prime}\left(\text { gasprice }_{t} * M P \text { Gquartile }_{m}\right)+\boldsymbol{\beta}_{\mathbf{2}}{ }^{\prime} \mathbf{z}_{\mathbf{a m t}}+\varepsilon_{a m t}
$$

where $y_{\text {amt }}$ is the fraction of vehicles of age $a$ and model $m$ that are scrapped between year $t-1$ and $t$.

The results from specification A.1 are presented in Table A.1. Gasoline prices do not affect the scrap rate of this newer set of used cars very much (in absolute terms) as they imply relatively small percentage changes in vehicle value. Instead, absolute changes in scrap rates concentrate in much older vehicles where maintenance and minor accidents yield a more flexible margin for the scrap decision. Overall, we find that when the gasoline price increases by $\$ 1$, vehicles with the best fuel-economy experience a decrease in their scrap rate by about -0.7 percentage point relative to cars in the lowest MPG quartile. The compositional effect grows with age. Among cars 10 years and older scrap rates in the highest MPG quartile fall by about 1.7 percentage points relative to the lowest quartile.

\section{First Stage and Reduced Form with MPG Turning Points}

The flexible specifications for the first stage and reduced form of the IV (equations (3) and (6) in the main paper) focus exclusively on relative changes in used vehicle values and scrap rates as gasoline prices move. This section describes an alternative specification that imposes more structure to allow for the estimation of "turning points" with respect to fuel economy. We now specify prices and scrap rates as a direct function of each vehicle's fuel economy. The model we adopt is similar to Li, Timmins and von Haefen (2009). Our data allows us to consider their approach not only for scrap rates, but also for used vehicle prices. We estimate the following models: 
Table A.1: The Effect of Gasoline Prices on Scrap Rates by MPG Quartile.

\begin{tabular}{|c|c|c|c|c|}
\hline & \multirow[b]{2}{*}{$\begin{array}{l}\text { All ages } \\
(1)\end{array}$} & \multicolumn{3}{|c|}{ By age category } \\
\hline & & $\begin{array}{c}\text { Age } 2-5 \\
(2)\end{array}$ & $\begin{array}{c}\text { Age 6-9 } \\
\text { (3) }\end{array}$ & $\begin{array}{c}\text { Age } 10-19 \\
(4)\end{array}$ \\
\hline Gasoline price $\times$ & $-0.254^{* *}$ & $-0.195^{*}$ & 0.104 & $-0.590^{* *}$ \\
\hline MPG quartile 2 & $(0.059)$ & $(0.095)$ & $(0.093)$ & $(0.105)$ \\
\hline Gasoline price $\times$ & $-0.503^{* *}$ & -0.143 & $0.296^{* *}$ & $-1.32^{* *}$ \\
\hline MPG quartile 3 & $(0.057)$ & $(0.091)$ & $(0.077)$ & $(0.107)$ \\
\hline Gasoline price $\times$ & $-0.675^{* *}$ & $-0.186^{*}$ & $0.298^{* *}$ & $-1.69 * *$ \\
\hline MPG quartile 4 & $(0.057)$ & $(0.090)$ & $(0.069)$ & $(0.108)$ \\
\hline$R^{2}$ & 0.145 & 0.109 & 0.156 & 0.160 \\
\hline Observations & 35,603 & 9,641 & 9,240 & 16,722 \\
\hline $\begin{array}{l}\text { Number of make- } \\
\text { model-age FEs }\end{array}$ & 7,305 & 1,798 & 1,688 & 3,819 \\
\hline
\end{tabular}

Notes: Coefficient values reflect percentage point changes. All models include fixed effects for each make-model-age and report $R^{2}$ for within-group variation. Change in scrap rate for the least efficient (first) quartile is omitted in order to allow fixed effects by age-year. Standard errors clustered by make-model-age. $*, * *$ indicate significance at the 5 and 1 percent level, respectively.

$$
\begin{aligned}
& p_{a m t}=\alpha_{a m}+\alpha_{a} t+\beta_{1} D P M_{m t}+\beta_{2} \text { gasprice }_{t}+\beta_{\mathbf{3}}{ }^{\prime} \mathbf{z}_{\mathbf{a m t}}+\varepsilon_{a m t} \\
& y_{a m t}=\alpha_{a m}+\alpha_{a} t+\beta_{1} D P M_{m t}+\beta_{2} \text { gasprice }_{t}+\beta_{\mathbf{3}}{ }^{\prime} \mathbf{z}_{\mathbf{a m t}}+\varepsilon_{a m t}
\end{aligned}
$$

where $D P M_{m t}$ indicates fuel cost and $\alpha_{a} t$ is a linear time trend that varies by age. Equations (A.2) and A.3 impose the restriction that vehicles at the extremes (highest and lowest $D P M$ ) will see the largest changes in price and scrap. Specifically, if $\beta_{1}<0$ and $\beta_{2}>0$, there exists a critical MPG-value above which used vehicle prices increase (or above which scrap rates decrease) when the gasoline price goes up. The reverse holds for scrap rates in equation (A.3).

Table A.2 reports the estimation results of specifications A.2 and (A.3), for all vehicles (columns 1 and 3) and for a restricted sample of vehicles ten years and older (columns 2 and 4). The coefficients on gasprice $_{t}$ and $D P M_{m t}$ have opposite signs in all four cases, allowing calculation of the "turning point" in MPG where the sign of the response changes. Turning points in the price and scrap regressions are similar for older vehicles, between 22 and 23 MPG.

To interpret the estimates in the table consider for example a vehicle with average MPG (20.0 in our sample): a $\$ 1$ increase in the gasoline price will decrease its price by $\$ 227$ and increase its scrap rate 0.34 percentage points. Vehicles with a fuel economy of $15 \mathrm{MPG}$ are predicted to respond much more dramatically: a $\$ 1$ gasoline price increase decreases their value by $\$ 786$ on average, and increases scrap rates by 1.56 percentage points. Conversely, high-MPG cars benefit from higher gas prices: the value of a $40 \mathrm{MPG}$ vehicle increases by $\$ 611$ following a $\$ 1$ gasoline price increase, while the scrap rate decreases by 1.49 percentage points. 
Table A.2: Price and Scrap Rate Effect as a Continuous Function of Fuel Economy.

\begin{tabular}{|c|c|c|c|c|}
\hline & \multicolumn{2}{|c|}{ Vehicle price } & \multicolumn{2}{|c|}{ Scrap rate } \\
\hline & $\begin{array}{l}\text { All ages } \\
\text { (1) }\end{array}$ & $\begin{array}{l}\text { Age } 10-19 \\
(2)\end{array}$ & $\begin{array}{c}\text { All ages } \\
(3)\end{array}$ & $\begin{array}{c}\text { Age } 10-19 \\
(4)\end{array}$ \\
\hline Gasoline price & $\begin{array}{c}3,409^{* *} \\
(167)\end{array}$ & $\begin{array}{c}1,450^{* *} \\
(126)\end{array}$ & $\begin{array}{c}-0.0091^{* *} \\
(0.0013)\end{array}$ & $\begin{array}{c}-0.0331^{* *} \\
(0.0024)\end{array}$ \\
\hline Dollars-per-mile & $\begin{array}{c}-61,020^{* *} \\
(3,376)\end{array}$ & $\begin{array}{c}-33,541^{* *} \\
(2,625)\end{array}$ & $\begin{array}{c}0.3173^{* *} \\
(0.0245)\end{array}$ & $\begin{array}{c}0.7301^{* *} \\
(0.0441)\end{array}$ \\
\hline$R^{2}$ & 0.349 & 0.127 & 0.064 & 0.072 \\
\hline Observations & 35,107 & 16,555 & 35,603 & 16,722 \\
\hline $\begin{array}{l}\text { Number of make- } \\
\text { model-age FEs }\end{array}$ & 7,191 & 3,768 & 7,305 & 3,819 \\
\hline MPG turning point & 17.9 & 23.1 & 34.9 & 22.1 \\
\hline
\end{tabular}

Notes: Estimation follows equations A.2 and A.3. All models include fixed effects for each make-model-age combination, and a linear time trend for each age. $R^{2}$ is reported for within-group variation. Standard errors clustered by make-model-age. *,** indicate significance at the 5 and 1 percent level, respectively.

The turning point specification has the nice feature of using continuous variation in fueleconomy, but suffers from the requirement that linear trends be imposed on prices and scrap rates over time 34 We find that this restriction leads to much less plausible results for newer vehicles in our sample: sharp effects of the recession, for example, cannot be absorbed by age-year fixed effects and could explain the asymmetric turning points in price and scrap shown in the tables. We therefore prefer the more flexible specification for our main elasticity estimates presented in Section II].

\section{Appendix B Evidence on Used Vehicle Transaction Costs}

\section{Summary Statistics on the Tenure of Used Vehicle Owners}

We employ a data set on used vehicle ownership tenure from R.L. Polk. The data set covers the period 2001-2012. A unit of observation is a used vehicle transaction recorded to the state department of motor vehicles. The data set contains all used vehicles that were transacted during the period 2001-2007 in eight states (Colorado, Idaho, Kentucky, Michigan, New Mexico, North Dakota, Texas and West Virginia) plus all subsequent transactions, including those in the period 2008-2012. Note, importantly, that all subsequent transactions of the same used vehicle are included, including those cars which are exported out-of-state. The total number of transactions in our data set is slightly over 61 million.

We calculate tenure as the time between two subsequent ownership-changing transactions of the same vehicle. Our sample limits the maximum observable tenure to 12 years (January 2001 - December 2012) for cars first transacted in 2001, but this truncation becomes more stringent

\footnotetext{
${ }^{34}$ Flexible age-year controls are incompatible with the turning point structure since they permit arbitrary increases or decreases in all prices and scrap rates together, leaving the turning point undefined.
} 
for cars that first transacted in 2007. We therefore restrict the sample to cars that transacted at least once during the period 2001-2002, although the results are very similar to those using the full sample. The restricted sample contains approximately 28 million observations ${ }^{35}$

Figure B.1 shows the distribution of vehicle age and owner's tenure. As the sample represents the universe of traded vehicles, the age distribution is smooth and spans a wide range from 0 to 30 years. The average tenure has a mean of 2.19 years with a standard deviation of 2.21 years: used vehicles are traded frequently ${ }_{36}^{36}$ Older vehicles are traded even more often. The average tenure for cars that were at least 16 years old at the time of transaction is 1.57 years (the standard deviation is 1.71 years). Figure B.2 shows that the tenure distribution shifts to the left as vehicle age increases. Of the vehicles that are 16-20 years old, 71 percent of the owners that we observe in the data sell their cars within the first two years of ownership. This percentage is even higher for 21-25 year old vehicles (76 percent) and vehicles over 25 years of age (86 percent). These statistics suggest that transaction costs for trading used vehicles are limited. Even vehicles with little value are traded every year and a half on average.

\section{Empirical Test for the Influence of Transaction Costs}

Transaction costs may cause some car owners to pay for repairs that exceed the price of a replacement vehicle. If the number of these "excess" (but rational given transaction cost) repairs moves significantly with gasoline price this could enter the scrap equation and influence our elasticity estimates. We test for this possibility using an asymmetry in the effect of transactions costs on aggregate scrap.

When relative vehicle prices change, some subset of owners will reoptimize their vehicle choice; the change in prices is large enough to overcome the transaction cost for a group on the margin. Since these people are changing to a different vehicle, the choice for the old one becomes sell or scrap. This reduces the number of excess repairs (since scrap will be preferred if the cost of repairs exceeds the car's value). For a vehicle whose price has increased, this effect works against the price-scrap effect we are trying to measure and mutes the elasticity. For a vehicle whose price has decreased, in contrast, the two effects work in the same direction. Therefore, to the extent transaction costs are important in our context, we expect the scrap elasticity to be muted (exaggerated) for vehicles that experience an increase (decrease) in resale value in any given period.

Table B.1 presents an empirical test of this asymmetry. We split the sample into vehicles whose price is expected to increase based on the first stage estimates and vehicles whose price is expected to decrease. We then estimate the IV and OLS specifications allowing separate elasticities for the two groups of observations. The direction of the effect in the table is as would be expected from transactions costs (elasticities are larger in magnitude for vehicles whose price has fallen) but the

\footnotetext{
${ }^{35}$ We do not observe the tenure of the last owner, as the data does not contain information on whether and when a vehicle was scrapped.

${ }^{36}$ We checked that these results are not driven predominantly by vehicles with very short tenures, such as dealerto-dealer transactions. Removing zero- or one-month tenure observations does not affect the outcomes very much: average tenure conditional on tenure lasting for at least two months is 2.42 years.
} 
Figure B.1: Summary Statistics: (a) Vehicle Age and (b) Owner's Tenure.

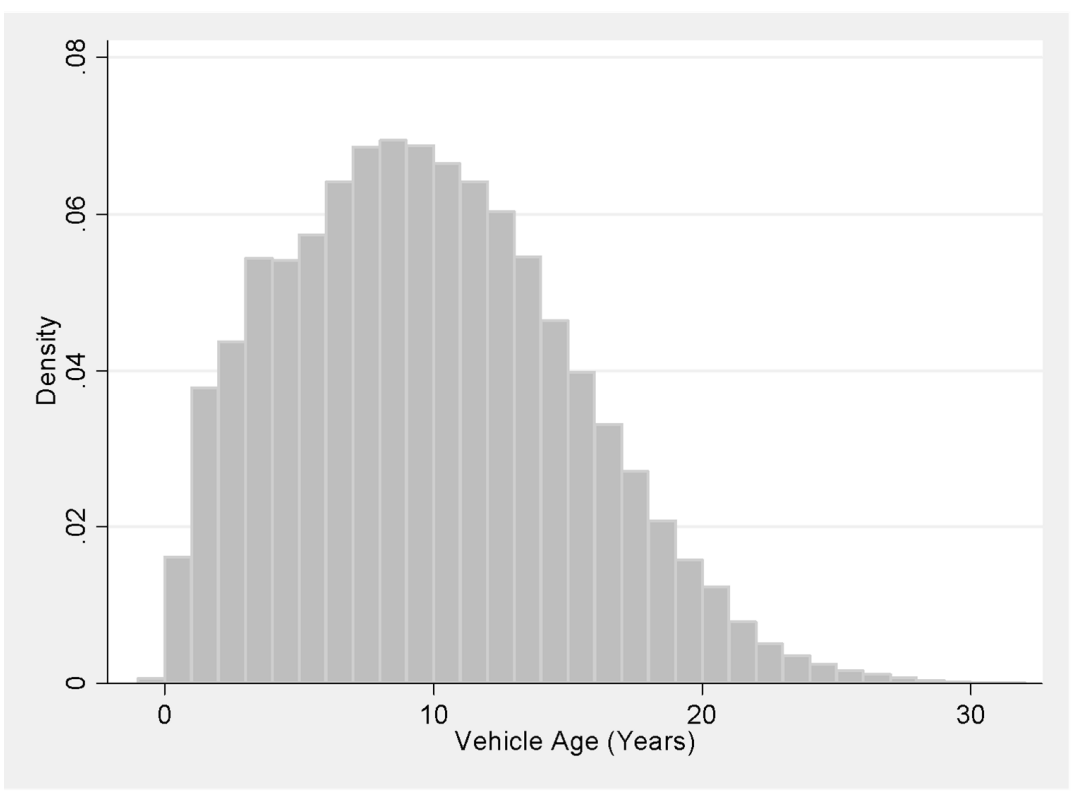

(a) Histogram of Used Vehicle Age at the Time of Transaction.

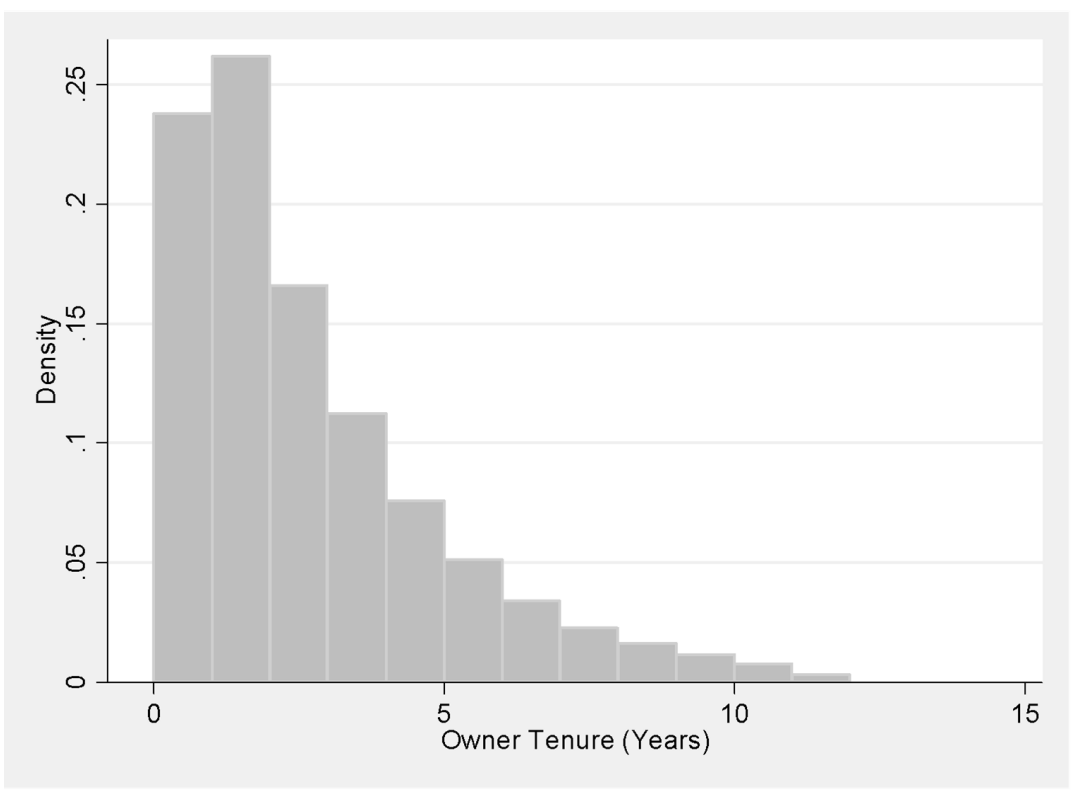

(b) Histogram of Used Vehicle Tenure.

Notes: Sample restricted to used vehicles that transacted at least once during the period 2001-2002. 
Figure B.2: Summary Statistics for Used Vehicle Tenure by Vehicle Age.

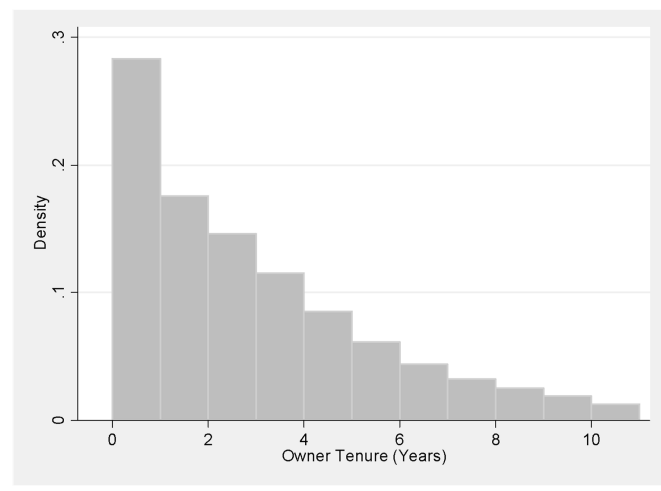

(a) Vehicle Age up to 5 Years.

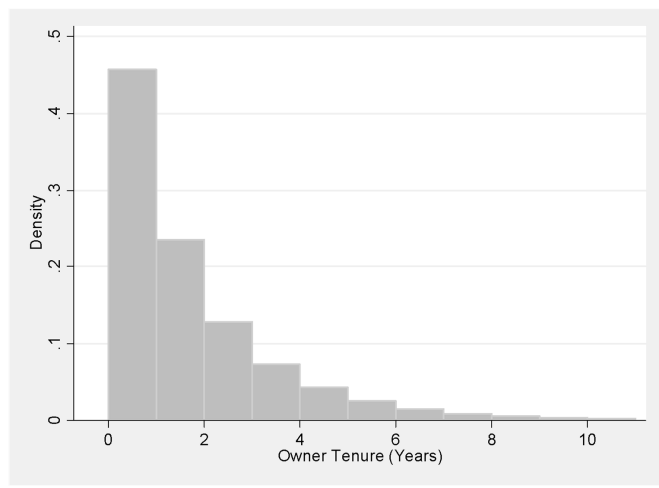

(c) Vehicle Age 11-15 Years.

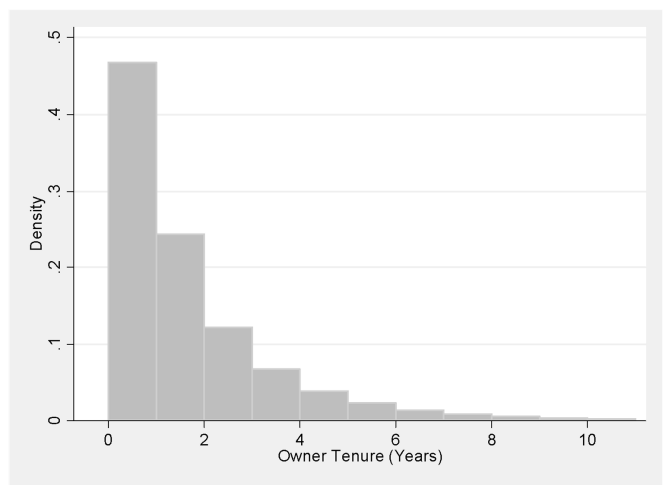

(e) Vehicle Age 21-25 Years.

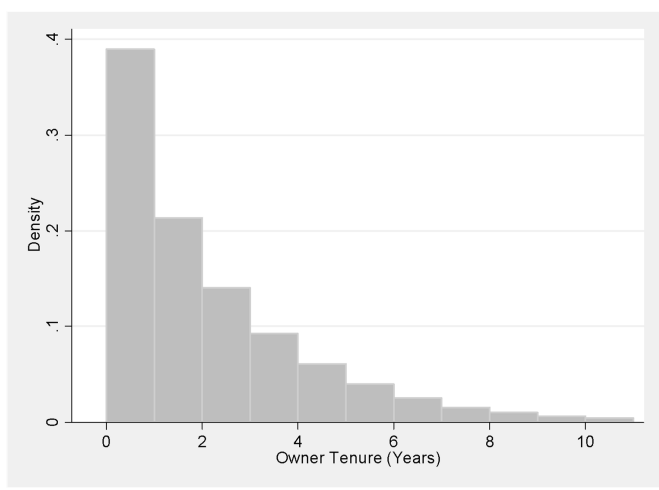

(b) Vehicle Age 6-10 Years.

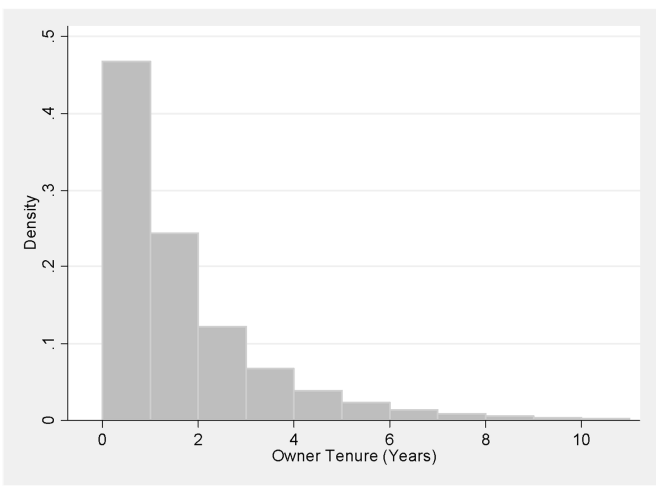

(d) Vehicle Age 16-20 Years.

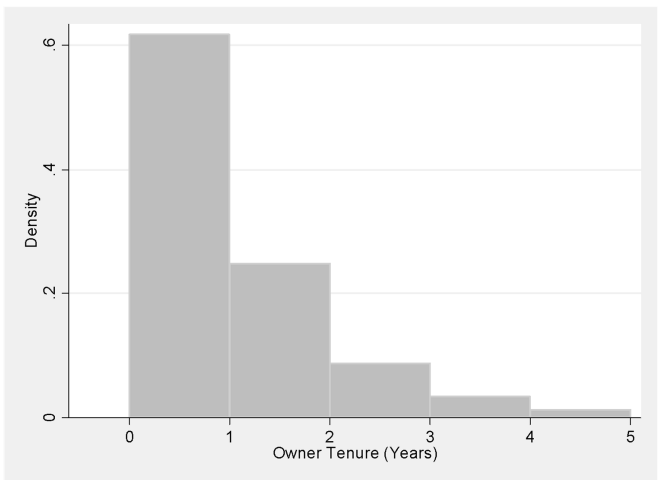

(f) Vehicle Age over 25 Years.

Notes: Sample restricted to used vehicles that transacted at least once during the period 2001-2002. 
size of the difference is very slight, suggesting that transaction costs have a limited influence in our setting.

Table B.1: Empirical Test for Asymmetry in the Effect of Transactions Costs on the Scrap Rate.

\begin{tabular}{|c|c|c|c|c|}
\hline & \multicolumn{2}{|c|}{ IV } & \multicolumn{2}{|c|}{ OLS } \\
\hline & $\begin{array}{l}\text { All ages } \\
\text { (1) }\end{array}$ & $\begin{array}{c}\text { Age } 10-19 \\
(2)\end{array}$ & $\begin{array}{l}\text { All ages } \\
(3)\end{array}$ & $\begin{array}{c}\text { Age } 10-19 \\
(4)\end{array}$ \\
\hline $\begin{array}{l}\text { Scrap elasticity } \\
\text { (predicted price increases) }\end{array}$ & $\begin{array}{c}-0.696^{* *} \\
(0.043)\end{array}$ & $\begin{array}{c}-0.656^{* *} \\
(0.041)\end{array}$ & $\begin{array}{c}-0.581^{* *} \\
(0.032)\end{array}$ & $\begin{array}{c}-0.479^{* *} \\
(0.037)\end{array}$ \\
\hline $\begin{array}{l}\text { Scrap elasticity } \\
\text { (predicted price decreases) }\end{array}$ & $\begin{array}{c}-0.709^{* *} \\
(0.043)\end{array}$ & $\begin{array}{c}-0.681^{* *} \\
(0.041)\end{array}$ & $\begin{array}{c}-0.584^{* *} \\
(0.032)\end{array}$ & $\begin{array}{c}-0.482^{* *} \\
(0.037)\end{array}$ \\
\hline$R^{2}$ & 0.232 & 0.276 & 0.237 & 0.314 \\
\hline Observations & 36,665 & 20,648 & 36,665 & 20,648 \\
\hline $\begin{array}{l}\text { Number of make- } \\
\text { model-age FEs }\end{array}$ & 5,657 & 3,197 & 5,657 & 3,197 \\
\hline
\end{tabular}

Notes: All models include fixed effects for each make-model-age combination, and a linear time trend for each age. $R^{2}$ is reported for within-group variation. Standard errors clustered by make-model-age. ${ }^{*}, * *$ indicate significance at the 5 and 1 percent level, respectively.

\section{Appendix C Elasticity Estimates from Alternative Models}

We first consider an alternative instrumenting strategy using the intuition of the quartile model in Equation (5). Table C.1 reports IV results - analogous to the estimates in Table 3 of the main paper - that directly import the estimates appearing in Table 2 as the first stage. The elasticity estimates are generally similar to the main specification, although the elasticity is somewhat larger for older used vehicles.

Table C.1: The Used Vehicle Price Elasticity of Scrappage with MPG Quartiles in the First Stage.

\begin{tabular}{|c|c|c|c|c|c|}
\hline & \multicolumn{5}{|c|}{ IV - First stage: quartile regressions } \\
\hline & \multirow[b]{2}{*}{$\begin{array}{l}\text { All ages } \\
(1)\end{array}$} & \multicolumn{4}{|c|}{ By age category } \\
\hline & & $\begin{array}{c}\text { Age } 2-5 \\
\text { (2) }\end{array}$ & $\begin{array}{c}\text { Age 6-9 } \\
\text { (3) }\end{array}$ & $\begin{array}{c}\text { Age } 2-9 \\
\text { (4) }\end{array}$ & $\begin{array}{c}\text { Age } 10-19 \\
(5)\end{array}$ \\
\hline Scrap elasticity $(\gamma)$ & $\begin{array}{c}-0.886^{* *} \\
(0.094)\end{array}$ & $\begin{array}{c}-1.134^{* *} \\
(0.195)\end{array}$ & $\begin{array}{c}-0.608^{* *} \\
(0.150)\end{array}$ & $\begin{array}{c}-0.924^{* *} \\
(0.127)\end{array}$ & $\begin{array}{c}-1.243^{* *} \\
(0.124)\end{array}$ \\
\hline$R^{2}$ & 0.196 & 0.189 & 0.198 & 0.189 & 0.184 \\
\hline Observations & 31,082 & 7,792 & 8,189 & 15,981 & 15,101 \\
\hline $\begin{array}{l}\text { Number of make- } \\
\text { model-age FEs }\end{array}$ & 5,466 & 1,226 & 1,234 & 2,460 & 3,006 \\
\hline First stage $F$-statistic & 52.07 & 50.01 & 53.77 & 58.41 & 40.08 \\
\hline
\end{tabular}

Notes: Fixed effects are for each make-model-age and each age-year combination. Standard errors are clustered by make-model-age. $R^{2}$ is reported for within-group variation. *** indicate significance at the 5 and 1 percent level, respectively. 
Table C.2 presents estimates from several additional alternative specifications of the model. We find that the scrap elasticity estimates are robust:

Small vs. large increases/decreases in gasoline price: The point estimates are similar for years in which the (absolute value of the) change in the gasoline price is above or below the median change. Hence, the elasticity estimates do not seem to be driven by years with large vehicle price shocks and consumer response seems relatively consistent through the range.

WLS weighted by registration counts: Weighting by registration counts gives more weight to common models in the elasticity estimation. The effect on the point estimate is small.

Make by model by year fixed effects: Allowing flexible patterns in scrappage by make-model-year (rather than make-model-age in our preferred specification) has little effect on the elasticity results. Controls for accident rate: We include annual accident rates at the make-model-age level on the right hand side of equation (2). We use data from the NHTS Fatal Accident Reporting System and so assume that accidents causing scrap are proportional to this measure. The estimated elasticity is not significantly changed.

Table C.2: Additional Elasticity Estimates from Alternative Models.

\begin{tabular}{|c|c|c|c|}
\hline & $\begin{array}{l}\text { Using large gas } \\
\text { price changes } \\
\text { (1) }\end{array}$ & $\begin{array}{l}\text { Using small gas } \\
\text { price changes } \\
(2)\end{array}$ & $\begin{array}{c}\text { WLS } \\
(3)\end{array}$ \\
\hline $\begin{array}{l}\text { Scrap elasticity }(\gamma) \\
\text { (All ages) }\end{array}$ & $\begin{array}{c}-0.642^{* *} \\
(0.072)\end{array}$ & $\begin{array}{c}-0.737^{* *} \\
(0.067)\end{array}$ & $\begin{array}{c}-0.707^{* *} \\
(0.069)\end{array}$ \\
\hline $\begin{array}{l}\text { Scrap elasticity }(\gamma) \\
\text { (Age 10-19) }\end{array}$ & $\begin{array}{c}-0.615^{* *} \\
(0.066)\end{array}$ & $\begin{array}{c}-0.614^{* *} \\
(0.062)\end{array}$ & $\begin{array}{c}-0.679^{* *} \\
(0.048)\end{array}$ \\
\hline $\begin{array}{l}R^{2} \text { (all ages) } \\
\text { Observations (all ages) } \\
\text { Number of make- } \\
\text { model-age/time FEs (all ages) }\end{array}$ & $\begin{array}{c}0.302 \\
17,764 \\
5,539\end{array}$ & $\begin{array}{c}0.165 \\
18,901 \\
5,648\end{array}$ & $\begin{array}{c}0.285 \\
36,665 \\
5,657\end{array}$ \\
\hline & $\begin{array}{l}\text { Make-model-year } \\
\text { fixed effects } \\
(4)\end{array}$ & $\begin{array}{l}\text { Controls for } \\
\text { accident rate } \\
\text { (5) }\end{array}$ & \\
\hline $\begin{array}{l}\text { Scrap elasticity }(\gamma) \\
\text { (All ages) }\end{array}$ & $\begin{array}{c}-0.815^{* *} \\
(0.049)\end{array}$ & $\begin{array}{c}-0.695^{* *} \\
(0.043)\end{array}$ & \\
\hline $\begin{array}{l}\text { Scrap elasticity }(\gamma) \\
\text { (Age 10-19) }\end{array}$ & $\begin{array}{c}-0.588^{* *} \\
(0.053)\end{array}$ & $\begin{array}{c}-0.647^{* *} \\
(0.040)\end{array}$ & \\
\hline $\begin{array}{l}R^{2} \text { (all ages) } \\
\text { Observations (all ages) } \\
\text { Number of make- } \\
\text { model-age/time FEs (all ages) }\end{array}$ & $\begin{array}{c}0.698 \\
35,276 \\
4,201\end{array}$ & $\begin{array}{c}0.236 \\
36,665 \\
5,657\end{array}$ & \\
\hline
\end{tabular}

Notes: All estimates here are variations on the make-model-age level instruments reported in Panel C of Table 3 . All include fixed effects for each make-model-age and each age-year combination and report $R^{2}$ for within-group variation. Standard errors are clustered by make-model-age. *,** indicate significance at the 5 and 1 percent level, respectively. 


\section{Appendix D Additional Simulation Model Output and Calcula- tions}

\section{VMT Data}

Table D.1 reports the average vehicle miles traveled measure that we use in simulation. The values are computed from the 2009 edition of the National Household Transportation Survey.

Table D.1: Average Miles Driven by Vehicle Age, Type and Size.

\begin{tabular}{|c|c|c|c|c|c|c|c|c|c|}
\hline \multirow[b]{2}{*}{ Age } & \multicolumn{2}{|c|}{ Car } & \multicolumn{2}{|c|}{ Light truck } & \multirow[b]{2}{*}{ Age } & \multicolumn{2}{|c|}{ Car } & \multicolumn{2}{|c|}{ Light truck } \\
\hline & Small & Large & Small & Large & & Small & Large & Small & Large \\
\hline 0 & 12,980 & 12,927 & 12,768 & 13,129 & 10 & 9,451 & 8,633 & 9,616 & 8,251 \\
\hline 1 & 12,459 & 13,273 & 13,775 & 14,222 & 11 & 9,827 & 9,320 & 8,933 & 9,596 \\
\hline 2 & 12,171 & 12,936 & 13,556 & 13,827 & 12 & 8,020 & 8,188 & 9,860 & 7,455 \\
\hline 3 & 11,796 & 12,057 & 12,878 & 13,166 & 13 & 7,334 & 7,716 & 8,445 & 7,342 \\
\hline 4 & 11,955 & 11,787 & 12,337 & 12,673 & 14 & 7,962 & 8,138 & 7,626 & 6,621 \\
\hline 5 & 11,827 & 11,525 & 12,212 & 12,589 & 15 & 7,677 & 7,012 & 6,517 & 6,479 \\
\hline 6 & 10,352 & 11,093 & 12,166 & 11,932 & 16 & 7,039 & 7,685 & 6,982 & 5,931 \\
\hline 7 & 10,761 & 10,593 & 9,962 & 12,266 & 17 & 8,417 & 6,692 & 5,902 & 5,703 \\
\hline 8 & 9,857 & 9,855 & 10,724 & 10,759 & 18 & 7,456 & 5,288 & 6,158 & 6,288 \\
\hline 9 & 9,839 & 9,715 & 10,821 & 10,329 & & & & & \\
\hline
\end{tabular}

Source: Data were obtained from the National Household Transportation Survey, 2009 edition.

\section{Simplified Leakage Calculation}

This section outlines a highly simplified version of our simulation model to provide a more intuitive calculation of the approximate leakage that we should expect. We then compare the results with the leakage results from the full simulation model. Additional details are available from the authors on request.

The calculation pools all used vehicle ages but maintains the division into four classes (car vs. truck and small vs. large). We use the following inputs:

- A fixed mileage for each vehicle of 10,450 miles per year.

- A scrap elasticity of -0.8 for all vehicles.

- Quantity-weighted average base scrap rates for the four types of vehicles: 9.1-9.4 percent.

- Average annual used vehicle price increases of $\$ 96, \$ 164, \$ 62$ and $\$ 92$ (for small cars, large cars, small trucks and large trucks, respectively) under the new CAFE standards relative to the old CAFE standards.

- Fleet sizes and MPG for each vehicle class following the data used in the full simulation. 
We first calculate how the used vehicle price changes in the policy run (new CAFE) translate to reduced scrappage relative to the reference case (old CAFE). The difference in annual scrap rates is 0.06-0.10 percentage points (on a base of 9.1-9.4 percent). The size of the vehicle fleet is 0.7 percent larger under new CAFE than in a counterfactual "new CAFE without leakage" scenario. We then multiply by the number of vehicles in each class and average annual gasoline consumption (10,450 miles divided by the average MPG of each vehicle class) to calculate leakage as the difference (between the "actual" and "counterfactual no leakage" policy experiments) in gasoline consumption. Fuel economy under the new CAFE standard increases by 0.57-2.01 MPG on average.

Using only the simplified data and inputs above, and introducing a fixed scrap elasticity of -0.8, we find that leakage calculated using the simplified model (13.9 percent) is close to the leakage result from the full simulation model (14.7 percent). This suggests that most of the effect operates directly through price-induced changes in the scrap rate as opposed to more complex general equilibrium effects in the simulation model. 